\title{
Bioenergy Crisis in Coronavirus Diseases?
}

\author{
Anirban Dutta ${ }^{1, *(1)}$, Abhijit Das ${ }^{2}$, Daniel Kondziella ${ }^{3,4}$ and Michal K. Stachowiak ${ }^{5}$ \\ 1 Department of Biomedical Engineering, University at Buffalo, Buffalo, NY 14260, USA \\ 2 Department of Neurology, The Walton Centre NHS Foundation Trust, Liverpool L9 7LJ, UK; \\ abhijit.neuro@gmail.com \\ 3 Department of Neurology, Rigshospitalet, Copenhagen University Hospital, 2100 Copenhagen, Denmark; \\ Daniel.Kondziella@regionh.dk \\ 4 Department of Clinical Medicine, Faculty of Health and Medical Sciences, University of Copenhagen, \\ 2200 Copenhagen, Denmark \\ 5 Department of Pathology and Anatomical Sciences, University at Buffalo, Buffalo, NY 14203, USA; \\ mks4@buffalo.edu \\ * Correspondence: anirband@buffalo.edu; Tel.: +1-716-645-9161
}

Received: 30 March 2020; Accepted: 16 April 2020; Published: 2 May 2020

Coronavirus disease (COVID-19) has been declared as a pandemic by the World Health Organization (WHO). Typical symptoms reported in COVID-19 are respiratory illness. About 80\% of the infections are not severe (even asymptomatic), whereas out of the hospitalized COVID-19 patients with pneumonia, about $50 \%$ developed hypoxemia by day eight while about $17-29 \%$ developed acute respiratory distress syndrome (Wuhan experience) [1]. Recently, neurological complications are increasingly reported [2], including encephalopathy in an elderly 74-year-old male [3]. The computed tomography (CT) scan of the head showed no acute abnormalities; however, the electroencephalogram (EEG) showed bilateral slowing and focal slowing in the left temporal region with sharply countered waves. This led to the possibility of subclinical seizures due to the presence of an area of encephalomalacia consistent with the prior history of embolic stroke, and the patient remained in the intensive care unit (ICU) with poor prognosis. Filatov et al. [3] found that elderly patients with such chronic conditions and with acute infections are at an increased risk of altered mental status even though COVID-19 did not cause meningitis or encephalitis in this case study. Nevertheless, Filatov et al. [3] case study highlighted the need to identify encephalopathy as a presenting sign of COVID-19, especially in cases with altered mental status including delirium, where severe cases can lead to long-term cognitive impairments.

Respiratory virus infections trigger inflammatory responses both at the site of infection (in the upper and lower respiratory tract) as well as systemically. Here, sepsis-associated encephalopathy (SAE) can be a transient and reversible brain dysfunction in patients with COVID-19, where a subgroup of critically ill patients can develop septic shock [4]. Anti-tumor necrosis factor (TNF) antibodies have been found in the blood and diseased tissues of COVID-19 patients [5]. The severity of inflammatory excess is due to the cascade of cytokine production, the cytokine storm, where TNF can act as an amplifier of inflammation [5]. Intracranial cytokine storms can result in blood-brain-barrier breakdown without direct viral invasion [6]. In fact, the endothelium is a principal organ involved in the pathogenesis of sepsis, leading to multiple organ failure [7]. The clinical spectrum of SAE can include sickness behavior, delirium, focal deficits, and coma [8]. The EEG features of SAE can include excessive theta rhythms, predominant delta rhythms, triphasic waves, and burst suppression along with seizures in up to $15 \%$ of patients. The review by Heming et al. [8] highlighted the use of various EEG monitoring tools in sepsis; however, Heming et al. [8] also found that the EEG monitoring methods remained ill-defined for sepsis. Heming et al. [8] reported that SAE is associated with neurovascular uncoupling due to microcirculatory dysfunction and low blood flow. Therefore, we postulate that the use of 
EEG monitoring will be more informative in conjunction with functional near-infrared spectroscopy (NIRS) such that any neurovascular uncoupling can be detected [7] during EEG events. Neurovascular coupling is important since it adapts local cerebral blood flow to the neural metabolic needs [9] that maintains the neuroenergetic status of the neurovascular tissue so any neurovascular uncoupling can lead to an energy crisis in the brain tissue [10]. Here, a majority of the energy in the brain is generated by the oxidative phosphorylation in the mitochondria where the energy currency, adenosine triphosphate (ATP), production rate plays a central role in brain bioenergetics [11].

Lee and Huettemann [10] presented a model in which inflammatory signaling changes the phosphorylation state of the mitochondrial proteins leading to inhibition of the oxidative phosphorylation. Since oxidative phosphorylation in the mitochondria generates a majority of the ATP so inhibition of the oxidative phosphorylation can lead to an energy currency crisis. Moreover, hypoxemia due to severe respiratory failure in respiratory virus infections can further aggravate the energy crisis. Powerful anti-inflammatory drugs can limit the inflammation but have the risk of increasing viral replication or bacterial infections [5], which can lead to meningitis/encephalitis [12]. Therefore, investigation of an adjunct therapy targeting dysfunctional mitochondrial metabolism [13] is proposed, including photobiomodulation [14], since ATP acts as a purinergic feedback signaling molecule where low ATP concentrations almost exclusively recruit microglial cells [15]. Purinergic signaling cascade is also involved with the complex vascular response at the capillaries (pericytes) [16], which can be partly responsible for the cerebrovascular complications of COVID-19 [7]. We further postulate that continuous fNIRS-EEG joint monitoring can be a useful bedside multimodal monitoring tool in neuro ICU [17] to detect transient neurovascular uncoupling. Continuous fNIRS-EEG joint monitoring will also be essential to monitor the effect of some sedative drugs that can affect neurovascular coupling and may increase the risk of delirium. However, patients in neuro ICU rarely undergo continuous brain monitoring along the lines of continuous electrocardiogram (ECG) in the cardiac ICU. Here, portable platforms with centralized multimodal data acquisition and signal processing have been found useful [18]. Moreover, some patients can be particularly susceptible to cytokine storms [19], where continuous brain monitoring can be necessary for triaging. Also, identifying genetic mechanisms underlying brain susceptibility to cytokine storms [19] will be important as predictors in addition to quantitative brain monitoring measures. Specifically, genetic insights into the mechanisms of fibroblast growth factor (FGF) signaling [20]. FGF signaling is increasingly being found essential for metabolic homeostasis in the tissues [20], where aberrant FGF receptor can enhance the Warburg Effect and mitochondrial dysfunction [21]. Recent data shows that FGF21 protects against hypoxia stress-induced injury in the cerebral microvascular endothelial cells [22]. So, FGF signaling can have a protective role not only in hypoxia-related brain disorders, e.g., encephalopathy, but also in neurodevelopmental disorders, e.g., schizophrenia [23], due to prenatal immune insult [24]. Without quantitative brain monitoring of the neuroenergetics and the functional genomics, deeper understanding of the early neurovascular signs of SAE will remain unfulfilled that is important for triaging and for tailoring the therapies.

Mitochondrial dysfunction related to microcirculatory dysfunction [8], with an inhibition of mitochondrial respiratory chain and a decrease of oxygen utilization, remains poorly understood [25]. An increased level of proinflammatory cytokines (such as TNF, interleukins, etc.) can affect various organs by affecting their mitochondrial energy homeostasis and vascular hyperpermeability where the initial effects can be found in the skeletal muscles, heart, liver, and lungs. Here, mitochondrial respiration, which seems to evolve during sepsis $[25,26]$, can be monitored using non-invasive broadband near-infrared spectroscopy of the cytochrome oxidase redox state [27] in various tissues including skeletal muscles. Yamane et al. [28] showed in severe influenza the relation between the host metabolic disorder-cytokine cycle and the influenza virus-cytokine-trypsin cycle in the skeletal muscles, heart, liver, and lungs (but not in the brain) which were driven by the cytokine storm. Immunomodulatory therapy has been proposed to improve the outcome in severe influenza [29]; however, its effects in the case of coronavirus disease are currently being evaluated (https://www.biocentury.com/article/304515) [30]. 
Nevertheless, human as well as animal studies are expensive and time-consuming so we propose a Phase- 0 paradigm for drug screening and personalized medicine using microglia-containing organoid models [31,32]. This is crucial since immunomodulation can be a double-edged sword where some patients can be more susceptible than others [19]. We also propose a mini-brain computer interface (see Figure 1) [33] that combines electrophysiological recordings (using Open Ephys [34]) and Vis-near-infrared (NIR) broadband spectroscopy [35] to monitor the neuronal as well as neurometabolic coupling state in the microglia-containing cerebral-vascular organoids. Figure 1 shows the experimental setup where a 32-channel 3D microelectrode array (MEA) based electrophysiological (Ephys) recording was combined with the broadband Vis-NIR spectroscopy of the activity of the mitochondrial Electron Transport Chain (ETC) complexes. Also, computational anatomy and functional genomics were performed on the organoids [23] that are proposed to investigate genetic mechanisms underlying brain susceptibility to cytokine storms [19] and bioenergy crisis.

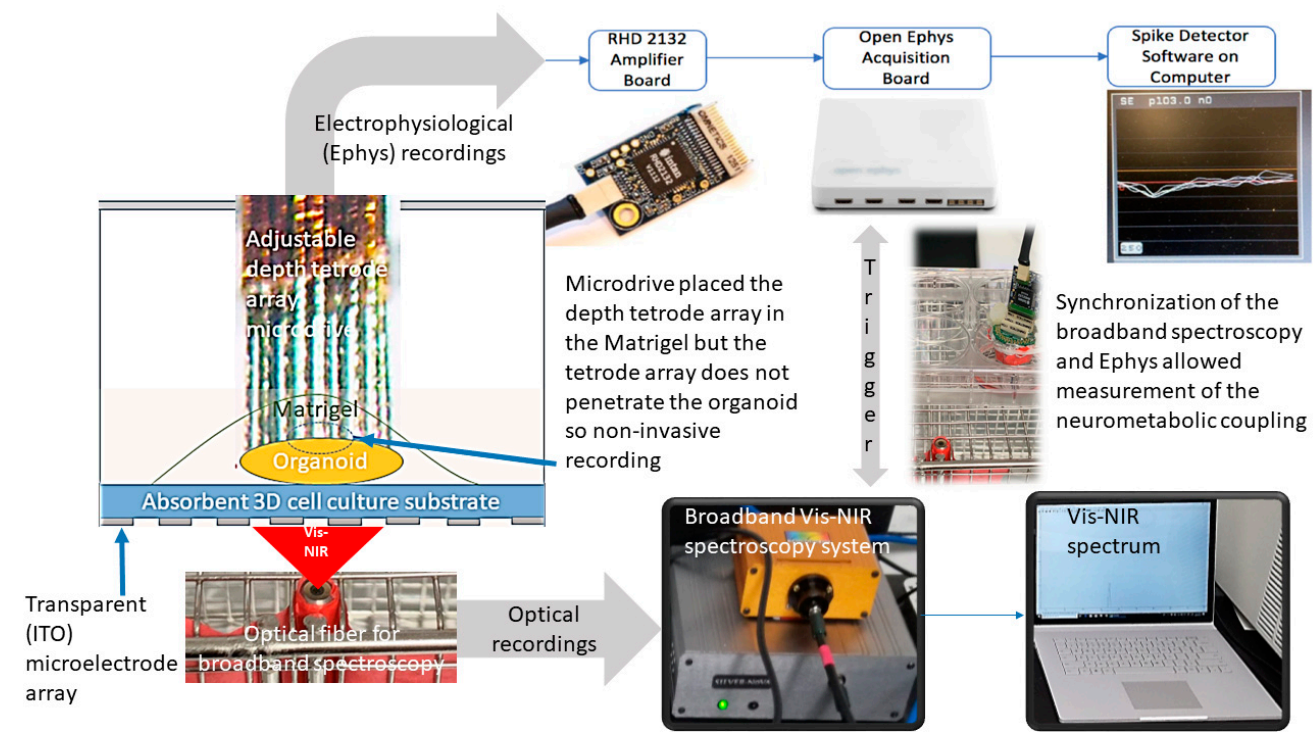

Figure 1. Mini-brain computer interface that combines electrophysiological recordings with the Vis-near-infrared (NIR) broadband spectroscopy to monitor the neuronal, metabolic, as well as neurometabolic coupling state in the cerebral vascular organoids (adapted from [33]).

In the subsequent human drug studies, broadband near-infrared spectroscopy of the brain [36] and the skeletal muscles can monitor the evolution of the systemic inflammatory response [37] to tailor the immunomodulation. An inexpensive solution using multi-wavelength continuous-wave (CW) NIRS-EEG multimodal monitoring has been developed for bedside continuous monitoring in the acute brain injury [38] to measure the neurovascular coupling (neuroenergetics) in the brain. Multiple wavelengths can be selected in the near-infrared optical windows [39] for robust CW-NIRS of the skeletal muscles and the brain where EEG in the case of the brain can provide additional metabolic disorder related features in the patients [40]. Here, the coupling relation of those EEG events, including non-convulsive status epilepticus, vis-à-vis multi-wavelength CW-NIRS-measured changes in the oxyand deoxyhemoglobin as well cytochrome oxidase redox state can provide a marker of the severity of SAE. Therefore, we postulate that the normalization of dysfunctional EEG features as well as the neuroenergetics (from neurovascular and neurometabolic coupling) may be a prognostic marker of intact recovery without long-term cognitive impairments in the critically ill COVID-19 patients with transient and reversible brain dysfunction due to SAE. Furthermore, we highlight the need to investigate continuous bedside monitoring of bioenergetics, including mitochondrial ETC complexes, in the skeletal muscles and the brain in sepsis. 
Author Contributions: Writing—original draft, A.D. (Anirban Dutta); Methodology, D.K.; Writing一review \& editing, A.D. (Anirban Dutta), A.D. (Abhijit Das), D.K., and M.K.S. All authors have read and agreed to the published version of the manuscript.

Acknowledgments: The support provided by the Community for Global Health Equity (CGHE) at the University at Buffalo (UB), Department of Biotechnology (DBT), Government of India, the Bill and Melinda Gates Foundation \& IKP Knowledge Park, India as well as UB NSF I-Corps program is gratefully acknowledged.

Conflicts of Interest: The authors declare no conflict of interest. The funders had no role in the design of the study; in the collection, analyses, or interpretation of data; in the writing of the manuscript, or in the decision to publish the results

\section{References}

1. Coronavirus COVID-19 (SARS-CoV-2)|Johns Hopkins ABX Guide. Available online: https: //www.hopkinsguides.com/hopkins/.//view/Johns_Hopkins_ABX_Guide/540747/all/Coronavirus_COVID_19_ _SARS_CoV_2_?refer=true (accessed on 11 April 2020).

2. Mao, L.; Jin, H.; Wang, M.; Hu, Y.; Chen, S.; He, Q.; Chang, J.; Hong, C.; Zhou, Y.; Wang, D.; et al. Neurologic Manifestations of Hospitalized Patients with Coronavirus Disease 2019 in Wuhan, China. JAMA Neurol. 2020. [CrossRef] [PubMed]

3. Cureus|Neurological Complications of Coronavirus Disease (COVID-19): Encephalopathy. Available online: https://www.cureus.com/articles/29414-neurological-complications-of-coronavirus-disease-covid19-encephalopathy (accessed on 29 March 2020).

4. Poston, J.T.; Patel, B.K.; Davis, A.M. Management of Critically Ill Adults with COVID-19. JAMA 2020. [CrossRef] [PubMed]

5. Feldmann, M.; Maini, R.N.; Woody, J.N.; Holgate, S.T.; Winter, G.; Rowland, M.; Richards, D.; Hussell, T. Trials of anti-tumour necrosis factor therapy for COVID-19 are urgently needed. Lancet 2020. [CrossRef]

6. Poyiadji, N.; Shahin, G.; Noujaim, D.; Stone, M.; Patel, S.; Griffith, B. COVID-19-associated Acute Hemorrhagic Necrotizing Encephalopathy: CT and MRI Features. Radiology 2020, 201187. [CrossRef] [PubMed]

7. Hack, C.E.; Zeerleder, S. The endothelium in sepsis: Source of and a target for inflammation. Crit. Care Med. 2001, 29, S21-S27. [CrossRef]

8. Heming, N.; Mazeraud, A.; Verdonk, F.; Bozza, F.A.; Chrétien, F.; Sharshar, T. Neuroanatomy of sepsis-associated encephalopathy. Crit. Care 2017, 21, 65. [CrossRef]

9. Chiarelli, A.M.; Zappasodi, F.; Pompeo, F.D.; Merla, A. Simultaneous functional near-infrared spectroscopy and electroencephalography for monitoring of human brain activity and oxygenation: A review. Neurophotonics 2017, 4, 041411. [CrossRef]

10. Lee, I.; Hüttemann, M. Energy crisis: The role of oxidative phosphorylation in acute inflammation and sepsis. Biochim. Biophys. Acta 2014, 1842, 1579-1586. [CrossRef]

11. Du, F.; Zhu, X.-H.; Zhang, Y.; Friedman, M.; Zhang, N.; Ugurbil, K.; Chen, W. Tightly coupled brain activity and cerebral ATP metabolic rate. Proc. Natl. Acad. Sci. USA 2008, 105, 6409-6414. [CrossRef]

12. Moriguchi, T.; Harii, N.; Goto, J.; Harada, D.; Sugawara, H.; Takamino, J.; Ueno, M.; Sakata, H.; Kondo, K.; Myose, N.; et al. A first Case of Meningitis/Encephalitis associated with SARS-Coronavirus-2. Int. J. Infect. Dis. 2020. [CrossRef]

13. Weinberg, S.E.; Sena, L.A.; Chandel, N.S. Mitochondria in the regulation of innate and adaptive immunity. Immunity 2015, 42, 406-417. [CrossRef] [PubMed]

14. Bhattacharya, M.; Dutta, A. Computational Modeling of the Photon Transport, Tissue Heating, and Cytochrome C Oxidase Absorption during Transcranial Near-Infrared Stimulation. Brain Sci. 2019, 9, 179. [CrossRef] [PubMed]

15. Domercq, M.; Vazquez, N.; Matute, C. Neurotransmitter signaling in the pathophysiology of microglia. Front. Cell. Neurosci. 2013, 7, 49. [CrossRef] [PubMed]

16. Cai, C.; Fordsmann, J.C.; Jensen, S.H.; Gesslein, B.; Lønstrup, M.; Hald, B.O.; Zambach, S.A.; Brodin, B.; Lauritzen, M.J. Stimulation-induced increases in cerebral blood flow and local capillary vasoconstriction depend on conducted vascular responses. Proc. Natl. Acad. Sci. USA 2018, 115, E5796-E5804. [CrossRef] [PubMed]

17. De Georgia, M.A.; Deogaonkar, A. Multimodal monitoring in the neurological intensive care unit. Neurologist 2005, 11, 45-54. [CrossRef] [PubMed] 
18. Busl, K.M.; Bleck, T.P.; Varelas, P.N. Neurocritical Care Outcomes, Research, and Technology: A Review. JAMA Neurol. 2019, 76, 612-618. [CrossRef]

19. Wurfel, M.M. Genetic insights into sepsis: What have we learned and how will it help? Curr. Pharm. Des. 2008, 14, 1900-1911. [CrossRef]

20. Nies, V.J.M.; Sancar, G.; Liu, W.; van Zutphen, T.; Struik, D.; Yu, R.T.; Atkins, A.R.; Evans, R.M.; Jonker, J.W.; Downes, M.R. Fibroblast Growth Factor Signaling in Metabolic Regulation. Front. Endocrinol. 2016, 6, 193. [CrossRef]

21. Senyilmaz, D.; Teleman, A.A. Chicken or the egg: Warburg effect and mitochondrial dysfunction. F1000Prime Rep. 2015, 7. [CrossRef]

22. Wang, H.-W.; Jiang, X.; Zhang, Y.; Wang, J.; Xie, J.; Wang, Y.-Q.; Li, Y.-H. FGF21 Protects Against Hypoxia Injury Through Inducing HSP72 in Cerebral Microvascular Endothelial Cells. Front. Pharmacol. 2019, 10. [CrossRef]

23. Stachowiak, E.K.; Benson, C.A.; Narla, S.T.; Dimitri, A.; Chuye, L.E.B.; Dhiman, S.; Harikrishnan, K.; Elahi, S.; Freedman, D.; Brennand, K.J.; et al. Cerebral organoids reveal early cortical maldevelopment in schizophrenia-computational anatomy and genomics, role of FGFR1. Transl. Psychiatry 2017, 7, 6. [CrossRef] [PubMed]

24. Powell, H. The Effects of Immune Factor, $\mathrm{TNF} \alpha$, on Human Fetal Neural Development and Schizophrenia in a Cerebral Organoid Model. Master's Thesis, State University of New York at Buffalo, Buffalo, NY, USA, 2019.

25. Balestra, G.M.; Legrand, M.; Ince, C. Microcirculation and mitochondria in sepsis: Getting out of breath. Curr. Opin. Anaesthesiol. 2009, 22, 184-190. [CrossRef] [PubMed]

26. Galley, H.F. Oxidative stress and mitochondrial dysfunction in sepsis. Br. J. Anaesth. 2011, 107, 57-64. [CrossRef] [PubMed]

27. Banaji, M.; Mallet, A.; Elwell, C.E.; Nicholls, P.; Tachtsidis, I.; Smith, M.; Cooper, C.E. Modelling of mitochondrial oxygen consumption and NIRS detection of cytochrome oxidase redox state. Adv. Exp. Med. Biol. 2010, 662, 285-291.

28. Yamane, K.; Indalao, I.L.; Chida, J.; Yamamoto, Y.; Hanawa, M.; Kido, H. Diisopropylamine Dichloroacetate, a Novel Pyruvate Dehydrogenase Kinase 4 Inhibitor, as a Potential Therapeutic Agent for Metabolic Disorders and Multiorgan Failure in Severe Influenza. PLoS ONE 2014, 9, e98032. [CrossRef]

29. Liu, Q.; Zhou, Y.; Yang, Z. The cytokine storm of severe influenza and development of immunomodulatory therapy. Cell. Mol. Immunol. 2016, 13, 3-10. [CrossRef]

30. Harrison, C. Coronavirus puts drug repurposing on the fast track. Nat. Biotechnol. 2020, 38, 379-381. [CrossRef]

31. Takahashi, T. Organoids for Drug Discovery and Personalized Medicine. Annu. Rev. Pharmacol. Toxicol. 2019, 59, 447-462. [CrossRef]

32. Ormel, P.R.; Vieira de Sá, R.; van Bodegraven, E.J.; Karst, H.; Harschnitz, O.; Sneeboer, M.A.M.; Johansen, L.E.; van Dijk, R.E.; Scheefhals, N.; Berdenis van Berlekom, A.; et al. Microglia innately develop within cerebral organoids. Nat. Commun. 2018, 9, 4167. [CrossRef]

33. Bhattacharya, M.; Freedman, D.; Stachowiak, E.; Stachowiak, M.; Dutta, A. Development of Bidirectional 'Mini-Brain' Computer Interface (mBCI) to Modulate Functional Neural Circuits-Stimulation and Recording from a Cerebral Organoid. Available online: https://www.researchgate.net/publication/329103836_ Development_of_bidirectional_'mini-Brain'_computer_interface_mBCI_to_modulate_functional_neural_ circuits_-_stimulation_and_recording_from_a_cerebral_organoid (accessed on 30 March 2020).

34. Siegle, J.H.; López, A.C.; Patel, Y.A.; Abramov, K.; Ohayon, S.; Voigts, J. Open Ephys: An open-source, plugin-based platform for multichannel electrophysiology. J. Neural Eng. 2017, 14, 045003. [CrossRef]

35. Hollis, V.S.; Palacios-Callender, M.; Springett, R.J.; Delpy, D.T.; Moncada, S. Monitoring cytochrome redox changes in the mitochondria of intact cells using multi-wavelength visible light spectroscopy. Biochim. Biophys. Acta 2003, 1607, 191-202. [CrossRef] [PubMed]

36. de Roever, I.; Bale, G.; Cooper, R.J.; Tachtsidis, I. Functional NIRS Measurement of Cytochrome-C-Oxidase Demonstrates a More Brain-Specific Marker of Frontal Lobe Activation Compared to the Haemoglobins. Adv. Exp. Med. Biol. 2017, 977, 141-147.

37. Hotchkiss, R.S.; Moldawer, L.L.; Opal, S.M.; Reinhart, K.; Turnbull, I.R.; Vincent, J.-L. Sepsis and septic shock. Nat. Rev. Dis. Primer 2016, 2, 16045. [CrossRef] 
38. Othman, M.; Bhattacharya, M.; Møller, K.; Kjeldsen, S.; Grand, J.; Kjaergaard, J.; Dutta, A.; Kondziella, D. Resting-state NIRS-EEG in unresponsive patients with acute brain injury: A proof-of-concept study. Neurocrit. Care 2020. [CrossRef] [PubMed]

39. Shi, L.; Sordillo, L.A.; Rodríguez-Contreras, A.; Alfano, R. Transmission in near-infrared optical windows for deep brain imaging. J. Biophotonics 2016, 9, 38-43. [CrossRef] [PubMed]

40. Faigle, R.; Sutter, R.; Kaplan, P.W. The electroencephalography of encephalopathy in patients with endocrine and metabolic disorders. J. Clin. Neurophysiol. Off. Publ. Am. Electroencephalogr. Soc. 2013, 30, 9. [CrossRef] [PubMed]

(C) 2020 by the authors. Licensee MDPI, Basel, Switzerland. This article is an open access article distributed under the terms and conditions of the Creative Commons Attribution (CC BY) license (http://creativecommons.org/licenses/by/4.0/). 